\title{
DIE GODSDIENSGEGEWE IN ENKELE HOOGTEPUNTE IN DIE PROSA VAN J. VAN MELLE
}

Dic prosawerk van. Johannes van Melle is groot in kwantiteit, maar nie altyd kwaliteit nie. Ondanks die ongelyke gehalte van sy oeuvre is die roman Bart .Nel en van die kortverhale soos "Oom Karel neem sy geweer saam", Oom Daan en dic dood", en "Oom Diederick leer om te huil", literĉre pieke in die Ouer Afrikaanse Prosa. Hulle sal selfs 'n toets aan huidige standaarde goed deurstian.

Van Melle het geskryf in die tyd toe Afrikanerwees outomaties Christenwees veronderstel het, en die kerk met wat daarby hoort, sentraal in die lewe van die Afrikaner gestaan het. Jonckheere (1968:181) nocm dit die "Calvinistiespuriteinse lewensgesindheid". 'n Historiese resepsic-ondersoek sal waarskynlik aantoon dat die implisiete en die werklike leser by die Ouer Afrikaanse Prosa meestal - en veral in die geval van Van Melle - saamval.

\section{DIE GODSDIENSGEGEWE IN BART NEI.}

Bart Nel speel, behalwe vir die periode in die tronk, af teen die tradisionele tydruimtc van plaas en plattelandse dorpie. In hierdie wêreld is 'n egskeiding ongewoon en onaanvaarbaar, soos ook " 'n dubbele hoereerdery" (183). Al is die Christelike geloof 'n onlosmaaklike deel van hierdie tydruimte is die figuur Bart tog nie, soos Jakob de. Jager in Anderkant die berge deur C.M. van den Heever, van die begin van die gebeure gedronge deur sy geloof nie. Hy word egter allermins as onverskillig en ongelowig gekarakteriseer; trouens, die outeur beeld sy ont wikkeling déúr'n proses van afstroping en verdieping van geloofslewe. Dat Bart hoër kyk as die intermenslike kom al gou na vore. In 'n gesprek met Fransina sê hy: "Ek sweer nie by 'n mens nie" (13), en teen oom Giel se argumente sê hy: "Daar is hoër bevele as dié van jou regeringf, Oom" (35)."

Die figuur Bart Nel word gekenmerk deur 'n sterk individualisme, wat 'n belangrike motief en struktuurmiddel word, in besonder weens die herhaling van die motief van 'n pad wat Bart allcen moet loop. Dit word deur verskeie stemme herhaal, die meeste deur Bart self. Wanneer hy gedurende 'n

- Aanhalings uit dic roman kom uit VAN MELLE, J. 1972. Bart Nel. Pretoria: Van Schaik. 
gesprek met Fransina agterkom dat hulle siening van sy plig in die Rebellie heeltemal verskil, dink hy: "Hierdie paadjie sal ek alleen moct loop" (16). Die gedagte kom deur innerlike monoloog na vore, terwyl dit ook in die direkte rede verwoord word wanneer Bart later in die werk na aanleiding van 'n mede-gevangene se geloof in die siener, sê: "Ek loop nie agter profesieë nie; ek loop met my eie oë by die lig wat ek het" (147). Die klimaks van hierdie siening kom in die erlebte Rede nadat Bart Fransina se brief ontvang het waarin sy om 'n egskeiding vra: "Ek kan alleen wees. Ek kan alleen staan. Alleen sal ck my pad deur dic beroerde wêreld loop" (149). Die woord "alleen" klink soos 'n akkoord en word nie net beklemtoon deur herhaling nie, maar ook deur die ongewone sintaktiese plasing in die laaste sin. In hierdie uitspraak, in teenstelling met die slot van die werk, speel God vir Bart nog geen noemenswaardige rol op die pad wat hy alleen loop nie.

'n Ander stem wat hierdie motief herhaal, is die verteller wanneer hy by Bart se vertrek van die kommando van Rooi Martiens meld dat Bart nou weer sy eie pad gaan (54). Die woorde dra hier letterlike sowel as figuurlike betekenis. 'n Derde artikulator van die alleen-loopmotief is Fransina. Wanneer sy Bart vir die cerste keer na sy vrylating sien, kom sy tot die insig dat hy 'n man is “wat moeilike en gevaarlike paaie alleen geloop het" (166). Later, tydens'n gesprek met haar vader, kom die alleen-motief weer aan die orde wanneer Fransina vir haar pa sê dat Bart alleen sal probeer deurkom (180).

In die epiese gebeure is daar twee opponerende bewegings in die ontwikkeling van Bart: 'n gestadigde afstropingsproses, wat in menslike terme 'n negatiewe beweging is, en 'n groei in die geloof wat uitloop op die positiewe beweging na "die ver ruim lig" soos wat Bart in 'n visioen sien. Ondanks die afstropingsproses tree Bart sec̈vierend uit die lewenstryd met "sy siel in hom". Hy is dus gestroop van alles totdat slegs die essensic oorbly. Wanneer daar alleenlik gekonsentreer word op wat hy verloor het in menslike terme, dan is Bart 'n tragicse figuur, want hy verloor dit deur sy eie toedoen, deur 'n karaktertrek, sy onwrikbare eiesoortigheid. Dic klem val egter op sy groei tot geloofsmens wat hom volgens die Christelike visie wat uit die werk blyk, allermins as tragies tipeer. Tussen die twee pole van die binêre opposisie van aan die een kant minder word en aan die ander kant meer word, groei 'n spanningselement.

Daar is verskillende trappe in die afstropingsproses wat in die lewe van Bart voltrek word. 'n Groot teleurstelling is dic onbevredigende afloop van die rebellic. 'n Belangrike deel van sy lewe voor die rebellic wat van hom afgeneem word, is sy vrou. Sy plaas, Kafferkraal word verkoop, en uiteindelik verloor hy ook vir Annekie. 
Die woord "het" wat op besit dui, staan in verband met die afst ropingsproses, en word 'n motiel, veral in die laaste vyf-en-veertig bladsye van die roman. Wanneer Bart uit die tronk kom, en dic oud-rebelle weer wegry nadat hulle hom geesdriftig verwelkom het, dink hy: "My Annekie, ... jou het ck darem nog" (155). Wanncer Annckie se tante haar kom haal, is die woorde "Ons het nou alles", swaar aan 'n dieper betekenis. Die het-motief eggo ook in die buurman, Maritz, se stelling: "Nou het jy niks meer nie ..." (199). Dan volg die klimaks van hierdie motief: "Hulle het nou alles," sê hy half uitdagend, "hulle het my grond, my vrou, my kinders. Maar my het hulle nie" (199). Hierdie uitspraak word vroeër voorberei wanneer Bart dink dat die mooi van huis en grond, van alles, af is as man en vrou nie meer vir mekaar omgee nie (145). In die laaste woorde van die werk, "en sy siel in hom" (200), is "het" implisiet teenwoordig; hy het nog sy siel. Waar Bart se begrip van besit uitstyg tot 'n geestelike vlak, bly dié van Fransina op aardse, menslike niveau wanneer sy aan Basson sê: "Jou het ek darem" (184). Bart en Fransina kan nic weer bymekaar uitkom nie, omdat sy nie geloofsgroei ondergaan nie. Sy bly eksistensieel, terwyl Bart geestelik wcg en hoër bewecg.

Voordat Bart saam met dic rebelle vertrek, kom daar weinig van enige godsdiensbelewing na vore. Eers in die veld begin die ander groot beweging in die werk, dic groei in die gcloof téén die afstroping in. Dit is die beginpunt en Bart luister nog maar met ' $n$ halwe oor na die diens wat deur 'n ouderling gelci word. $\mathrm{Hy}$ is dan ook "een van die agterstes" van dié wat luister. Tog is hy nie onverskillig nie en "bring die aand vir hom nog 'n troos" (55), en voordat hy aan die slaap raak, mompel hy die laaste twee rec̈ls van die psalmvers wat dic rebelle vroeër in die aand by die gorlsdiensocfening gesing het.

Wannecr Bart gevang word, gaan die afstropingsproses voort, maar ook die geloofsgroei. In die tronk luister hy, maar nog nie in oorgawe nie, na iemand wat staan en preek. Tog raak dit Bart, want hy vra wie die man is. In hierdic stadium van sy lewe sien hy nog die dinge "sonder hulle goed te begryp" (137). Oom Gawie met sy sakbybeltjie is 'n instrument op Bart se pad na geloofsmens. Toe hy van die huis af weg is, was godsdiens so ver van sy gedagtes dat hy nie 'n Bybel saamgeneem het nie: "die gedagte daaraan het nie by hom opgekom nie" (139). Ook Fransina het nie daaraan gedink nie. Bart se besluit om oom Gawic se Bybel af en toe te leen, motiveer hy deur middel van innerlike monoloog. Hy voer nie aan dat hy vertroosting in die Woord soek nic, maar sien dit as iets om te lees teen die verveling in die tronk.

Wanneer oom Gawie se tyd verstreke is en Bart agterbly, is dit duidelik dat Bart wat godsdiens betref, verander het. Oom Gawie laat sy Bybel agter. 
Daar word deur die verteller gesuggereer dat Bart in die tyd wat verby is, wel uit die Bybel gelees het, want na oom (Gawie se vertrek, lees Bart "meer as vrocër" daaruit (151). Nou word daar vir die eerste keer gemeld dat Bart vertroosting uit die Bybelwoord put. Deur die verteller word indirek aangedui dat Bart troos in die Bybel vind: "... in dic Bybel vind 'n rebel troos, meer nog as ander mense" (151).

Die binêre opposisie kom duidelik na vore wanneer Bart weier om Fransina terug te neem. Die een groot beweging, die afstropingsproses, is so ver voltrek dat Bart sy vrou en sy eiendom verloor het. Tog is daar duidelike tekens van die ander groot beweging, die groei in die geloof. Die feit dat hy Fransina nie weer wil terugneem nie, motiveer hy uit die Skrif. Hy is oortuig daarvan dat die Here so 'n daad nie sal goedkeur nie, want dit sal " 'n dubbele hoereerdery" wees (183) en "die cen gruwel op die ander" (183). "Hocreerdery" en "gruwel" is woorde wat nie vreemd is aan Bybelse taal nie. Hoewel Bart se trots en koppigheid herhaaldelik beklemtoon word, speel sy christelike lewenshouding 'n belangrike rol wanneer hy Fransina afwys.

Die enigste persoon wat Bart uit sy lewe voor die rebellie oorhou, is Annekie, en in hulle verhouding speel godsdiens ' $n$ rol. Die verteller meld dat hulle saam bockevat en dat dit nie daarby bly nie, maar dat dit uitloop op gesprekke oor Bybelse sake en oor die wil van God. Die afleiding kan gemaak word dat dit ook gaan oor die doel van God met Bart en Annekie se lewens. Dat dit nie vir Bart meer om die samesyn met Annekie gaan as om die inhoud van die gesprekke nie, word bewys deurdat hy by hul afskeid vra: "Sal jy elke dag in jou Bybel lecs?" (198).

Aan die einde van die werk assosieer Bart sy lewe met dić van Job: "Kaal het ek op die wêreld gekom en kaal sal ek daaruit gaan" (200). Die woorde veronderstel 'n kennis van die geskiedenis van Job by die werklike leser. Daarsonder gaan die suggestie verlore dat Bart, soos Job, deur God getoets is, met ander woorde dat wat met Bart gebeur het in die hand van God was. Soos die Bybelfiguur kom hy gelouter dcur die beproewinge anderkant uit, gestroop van dic dinge wat eers vir hom belangrik was.

Maar die belangrikste, die Christelik essensiële, sy siel, het hy behou. "Die ver ruim lig" wat hy in die visioen tegemoet loop, kan gesien word as die toekoms, of 'n nuwe lewe waarin hy al die ou dinge afgeskud het. Teen die agtergrond van Bart se geestelike verdieping en sy groei téén dic afstropingsproses in na geloofsmens, het "die ver ruim lig" egter ook 'n religieuse konnotasie, naamlik die ewige lewe. 
Dit kan voorkom asof die klem in die werk val op hoe alles van Bart weggeneem word. Die kruks is egter dat Bart'n oorwinnaar in dic geloof is.

\section{GODSDIENS EN DIE DOOD IN ENKELE KORTVERHALE}

Nog sterker as in die beelding van die weerbare, strydende karakter, figureer dic godsdiensmotiel in dic beelding van karakters in hulle weerlooshcid voor die dood. Dit is die geval in die kortverhale "Oom Daan en die dood", "Oom Karel neem sy geweer saam" en "Oom Diederik leer om te huil".

In die kortverhale, soos ook in die langer verhalende werke van Van Melle, hang die tema van die tydelikheid en die broosheid van menslike verhoudinge, saam met die verganklikheid van alles. Dit is dus nic verrassend dal die dood dikwels in die skrywer se werke voorkom nie. Jonckheere (1968:50) beskou die verhale met die dood as "dramatisch handelingsmoment", as 'n hoogtepunt in Van Melle se prosa.

In al drie bogenoemde kortverhale bespiegel die hoofpersonasies, die drie ooms, oor die dood. Oom Daan ("Oom Daan en die dood") word gekarakteriseer as iemand wat nic normaalweg oor geestelike dinge peins nie. Trouens, hy word geskets as hard, onbetroubaar en onregverdig, kenmerke wat nie by die ware Christen hoort nie. Gedagtes aan die dood word by hom aangewakker deur sy seuntjie wat bonatuurlike vermoëns besit deurdat hy voorbodes van mense se dood sien. Oom Daan praat van die kind se "vooruitsiendheid".

$\Lambda \mathrm{I}$ word hy nic as Christen gekarakt iseer nie, word dit gesuggereer dat hy in elk geval aan 'n lewe na die dood glo: " 'n Mens weet nic hoe dinge is ná jou dood nie. Daar anderkant is miskien dinge waarvan ons hier geen vermoede het nie" (136).*

Oom Daan se inkeer kom nie uit geloofsoortuiging nie, maar gaan suiwer om homself. Dit word in soveel woorde gesê: "Ja, so is hy nou. Hy het nie na ander gekyk nie; hy het net na homself gekyk" (137). Die Christelike naasteliefde ontbreek by hom, en hy het ook nie dic gclowigc se gerusstelling dat hy na sy ewige huis gaan nie. Oom Daan is bang vir die dood, want hy vrees dat hy verant woording moet doen vir dinge wat hy in sy lewe verbrou het. Al word daar nêrens gesê dat hy 'n Christen is of sells dat hy in 'n Christelike wêreld staan nie, wcet hy wat volgens Bybelse norme reg en verkeerd is.

- Aanhalings uit "Oon Daan en die dood" en "Oom Karel necm sy geweer saam" kom uit VAN MELLE, J. 1938. (lom l)aan en die dond. Bloemfontein: Nasionale Pers. 
Anders as oom Daan, is oom Karcl uit "Oom Karel neem sy gewer saam", nie bang vir die dood nie. Dat daar ' $n$ hemel is, en dat hy na sy dood die saligheid gaan beërwc, betwyfel hy vir geen oomblik nie: "Dat hy hemel toe gaan, is vir hom 'n uitgemaakte saak; dit was altyd vir hom 'n uitgemaakte saak gewees vandat hy 'n kind was" (15I). Oom Karel word gekarakterisecr as gelowige met kennis van die Bybel soos onder andere blyk uit die woorde uit Job wat hom te binne skiet wanneer hy aan sy omstandighede en aan die naderende dood dink: "En.Job was oud en cler dagen sat" (148). Dat hy dic Bybel ken en graag lecs, kom in cen van die talle vergelykings wat oom Karel gebruik, na vore, wanneer hy dink hoe goed hy die Bosveld ken: "Hy ken dit alles so goed as hoofstukke in dic Bybel, nog altyd fris, altyd bekoorlik" (154). Sy vertroue in die Here blyk uit sy bespiegelinge oor die hemel, waar soos hy redenecr, die Here mense soos hy nóg kan gebruik, en in die gevegte waaraan hy in die hemel gaan declneem, sal belioed: "Maar altyd worl lulle deur die Here beskerm" (156-157). Daar kom nog 'n Bybelse verwysing voor waar dic ou predikant aan oom Karel wil duidelik maak dat daar vrede in die hemel hecrs, en Jes. 11:6 en 7 aanhaal.

Die krisis waarvoor oom Karel staan, is die vraag of daar in die hemel ook vir icmand soos hy, jagter en krygsman, plek sal wees. Hy voel ecnsaam, nutteloos en oorbodig, maar huiwer ook vir die naderende dood omdat hy vrees dat die hemel nic vir iemand soos hy voorsiening maak nic. 'n Sleutelbegrip in hicrdic kortverhaal is dic dood. Dic woord self en uitdrukkings wat daarop dui, kom herhaaldelik voor. Op die eerste bladsy klink dit al dric keer namekaar: "Sy ou vrou is dood. Sy ou jagmaats is dood; sy ou krygsniakkers is dood en weg" (147). Die naderende dood word herhaaldelik deur middel van vergelykings wat in die ruimte van die verhaal geinntegreer is, beklemtoon, deur onderskeidelik oom Karel en die verteller. Die verteller meld byvoorbeeld dat oom Karel leef soos " 'n vat wat leegloop; 'n dam wat aan dic opdroë is"' (149).

Herhaling van woorde speel 'n belangrike rol by die suggestie van oom Karel se naderende dood. Belangrik hier is die woord "ou" en "oud" wat teen 'n hoë frekwensic voorkom. "Oud" implisecr na aan dic einde, dit wil sê dic dood: "oud en der dagen zat" (148), "ou perd", "ou vrou", "oud en oorbodig", "ou pad", "ou jagmaats", "ou man" (149), "ou man", "ou man", "jy moet self oud wees", "ou mens" (150 - alles in 'n paragraal van vyf rcëls), "soos 'n ou hond", "jou ou hond", "soos 'n ou hond", "soos 'n ou perd" (151), "my ou maat" (152), "ou maat", "ou skietveld", "ou plekke" (153), "ou omgewing" (155), "ou man", "ou jagmaats" (156), "ou man" (159).

Die kortverhaal begin met ' $n$ beskrywing van dic veld. Dit is in ooreen- 
stemming met oom Karel se geestesgesteldheid en gesicn vanuit sy perspekıicl: "ou oom Karel Stone sil iu die koclte langs sy huis en $k$ jk na die veld ..." (147) (my kursivering). Die beskrywing het dic dondsgedagte as ondertoon gesuggereer deur woorde soos "lecg", "eensaam", "droewig". Dic verhaal begin net "Ou oom Karel Stonc ..." en dan word hy onmidrlellik in die winterse ruimte greplaas: "geelwil gras", "dle bleckblou winterlemel, "bleck hemel" (147). Hierdie woorde staan in die ecrste paragraaf. 1)ic tweede paragraaf slaan 'n brug tussen dic menslike figuur en die natuur, want dic natuur word nou deur middel van personifikasic beskryl: "sprakeloos" en "dlocwig". In dic vierde paragraal word die menslike liguur, oom Karel, se gevoclens beskryl. Dic hegte struktuur van die kortverhaal wat under andere deur herhaling bewerkstellig word, is in hierdie paragrawe opvallend. (Oom Karrl vocl 'n lecgte in hom wat deur middel van 'n vergelyking verbind word aan die natuur: "soos in die veld en in dic hemel". Die woord "lecgte" in hicrdie paragraal skakel mel "leeg" in dic verbindingstuk tussen mens en natuur. "Lecgte" word geassosicer met censaamheid. Eers word 'n natuurgegewe as eensaam geskẹts: "I) bulte lê daar consaam ...", en dan skakel dit niet die hoolliguur wat niks het om na uit te sicn behalwe "lecgte cn ecnsaamleeid" nie. Hicr word die twee woorde saam gebruik. Dic ecnsaamheidsmot ief herhaal later in dic paragraal vanuit die gedagtes van oom Karel, dat hy clke jaar ecusamer word. Dic parallel tussen mens cn natun word nie net gesuggereer nie, maar ook uitgespel: "... en stadigaan word hy soos die winterveld, stil, leeg" (148).

'n Verdere woord wat deur herlialing struktuurmiddel word, is "droewig" cn variante, wat weer die oorecnkoms tussen die naluur en die hoolliguur se: gemocdsgesteddheid onderstrecp.

Eers is dit die lug en dic veld wat vamit oom Karel sc perspekticf "droewig" is. Dan vocl oom Karel 'n droefnis om die dinge: wat nie meter daar is nic, en onmiddellik word dit geskakel met dic natuur, want in die eerste decl van die sin dink hy dat hy "n leegte in hom vocl "soos in die veld en in dic hemel". Twee paragrawe verder kommunikecr hierdie mot ief wecr wannecr daar'n "vac: weemocd" by oom Karcl opkom (148).

Hocwel die natuur by Van Melle 'n belangrike rol specl, word dit nooit 'n mag wat aanbiddenswatrdig is nie, soos by (.M. van den Heever in sy werke met panteïstiese trekke.

Oom Karel se krisis word tecn die agtergrond van die winter geskets. Hy kom $10 t$ klaarheid in die Bosveld wanneer dit lente word. Vanuit oom Karel se perspektief het Bosveld en henel raakpunte. Die dool het vir hom die assosiasie van "huistoe trek" (1.50); sy aardse huis waar hy tuisvocl, is nie by 
sy kinclers nie, maar clie Besveld waaraan hy dink as "dic huis" waar hy dag na dag meer tuis vocl (1.54). $\mathrm{Al}$ is oom Karel se oplossing van die problecen redelik onkonvensioncel, kom dit vanuil sy Christenwees.

( )ndanks dieselfide tydruimie en 'n verwante problecun verskil oom Daan en oom Karel henelslorecel. Die een word Godloos geteken en die ander as lewenslange gelowige. Die beskrywing van hulle eincle illustrecr hierdie kontras. Oom Daan worstel en praat ylende "van dinge wat hy moct regmaak" (146). Oom Karel sterf in die vrede van die gelowige: "Hy lyk mooi soos hy nou daar lê. 'n Mooi ou man, kalm, vredig met icts wat na blydskap lyk oor sy gesig" (159).

()om Diederik ("Oom Dicderik leer on te huil") val in clieselfeke katcgorie as oom Karel, in die sin dat albri oortuigde (horisten-gelowiges is, al kom dit in cersgenoemde kortverhaal ecrs in die laaste helfte na vore. Dat oom Diederik 'n probleem lict waaroor hy pieker, word al gou duidelik wanneer genocm word dat hy "weer in gepeins" verval (142). Oom Diederik self besel rlat hy nie meer met sy vrou praat nic omdat hy "so met sy eie geclagtes besig is dat hy die geselskap verwaarloos" (143). Soos oom Karel is hy ecnsaam tussen sy mense. Daar word nic gesê waaroor hy so baie dink nic, maar dit word gesuggereer dat dit oor die onderwerp van sy droom tydens sy siekte is. In die droom loop sy denke "ecen rigting" (144): waller vereiste gaan dlaar aan hom gestel word om dic ewige lewe te beërwe. Soos oom Daan en oom Karel, is oom Diederik dus ook besig met gedagtes aan die dood.

Hicrdic kortverhaal is 'n soort kadcrverhaal met sy sickte en die tydperke daarvoor en daarna as dic buitenste verhaal, en die droom as dic binneste. Sy reis met kar en perde na dic moni groot kerk met sy vensters wat blink in die son, is 'n P'elgrim se reis na die erengheid in die kleine. Dié bestemming word aangedui deur oom Diederik se ant woord op dic vraag waarheen hy ry: Hy ant woord dat hy op) pad is na dic plek "waar almal hecn ry", dit wil sê dic dood (146). Dic werk met sy duiclelike religieuse inslag is geplaas in dic Cluristelike rumte wat so tipies van dic (Ouer Afrikaanse Prosa is.

'n Oorcenkoms mel oom Daan is dat oom Diederik ook angs ervaar op sy pelgrimsiog na dire ewigheid. Hier hou dit egter op, want diar word nooit gesuggerecr dal oom Daan 'n oortuigde. Christen is nie, terwyl dit hy oom Diederik beslis die geval is. Op sy reis na die ewige lewe kom hy hekwaglers teé, wat besluit of hy aan sekere vereistes voldoen om deurgelaat te word. Wecr tipies van die Oucr Alrikaanse Prosa is dic saamgaan van gocie Nrikancrskap en gocic (hristenskap. Aan dié vereiste van vaderlandsliefde voldoen oom Diederik. Aan die volgende voldoen hy onk, maar nie so maklik nic. Waar dic vorige vereiste om licfde tot jou eic mense gaan, is die 
norm hier liefde tot '" ander nasic, in hierdie geval oom Diederik se "swart skape" wat hy moes laat wei. Hierdie woorde verwys na Jesus se gesprek inct Simon P'etrus in Johamnes 21.

Oom Diederik leet wel iets anan die sendingsopelrag van die gelowige gedoen deur sommige van sy swant werkers dic hoisgodseliens te latat bywoon. Met twee van sy werksmense het hy verder gegaan cn onr geloofsake gepraat. Met Winclvö̈l het oom Diclerik gefaal, want ondanks lang gespekke het Windvö̈l "ie min verstand geliad on vecl daarvan te begryp" (149). Met Vaatije, die Swat man saam mot wie hy grootgeword het, hel hy dikwels oor dic gelool gepraat.

Tot hice het oon Diecierik aan die gebod van liefle to jou naaste voldoen. By dic laaste hek word hy egter weggewys omdal hy nog nic gelec: huil het nic. Dic antwoord op hicrdie raaiselagtige norm, kry oom Dicderik in dic gecleclte vau die Bybel wat die dominec woortecs: "Ln als Ifij nabij kwam en de stad zag, weende Hij over haar" (Van Melle word hier op 'n onnoukeurigheid betrap. Hy noem dat dié woorde uit Matthéüs 19:4l kom Dit staan egter in Lukas 19:41). Die sondige. Jerusalem waaroor.Jesus gehuil het, word in die Van Mclle-verhaal simbool van die hele sondige wêreld. Dit word gesuggererer dat die licfde tot die naaste, wat spruit uit licfle tot God, nic voldoende is as die (horisten nie liclite en verdriet voel vir die ganse mensetom nie. Dic tranc moct "aanhou vloci solank dic menselom in nood en sonde lecf" (156).

Aan die einde van dic verhaalgebeure in "Oom Karel neem sy geween saam" is die problecm opgelos, maar in dic geval van oom I )icelerik nic. Hy word wel deur 'n groot droefheid vervul, matar dit is ondat hy nog nooit geleer het om die regte trane te huil nic. Ware Christen wat hy is, soek hy troos in die gebed en birl hy on "daardie droclheid wat sal anhou; aanhou solank die son op 'n onveranderde aade skyn" (157).

Die kron waarop hierdie kortverhaal gebou is, is 'n (hristelike norm: liefle lot (ind co licfile tot die naaste. Jonckheere (1968:54) praat in hierdie verband van "de centralc, intens christelike idce". Anders as by oom Daan spruit oom I dicklerik sowel as oom Karel se besimning oor dic dood uil 'n deurlecte Christelike lewenshouding.

Soos dic godsdliensgegewe 'n rol speel in Bart. Nel en die dric bespreckte kortverhale, is dit ook die geval in die meeste werke van Van Melle. Hocwel hy in sy verhaalkuns sy tydgenote in sommige opsigte vooruit is, is hy wat die Christelike tydruinte van sy prosa betrel, kind van sy tyd. 


\section{BIBLIOGRAFIE}

\section{Gebruikte tekste}

VAN MELLE, J. 1972. Bart Nel. Pretoria: Van Schaik.

VAN MELLE, J. 1938. "Oom Daan en die dood". (In Oom Daan en die dood). Bloemfontein: Nasionale Pers.

VAN MELLE, J. 1938. “Oom Karel neem sy geweer saam". (In Onm Daan en die dood). Blocmfontein: Nasionale Pers.

VAN MELLE, J. 1938. "Oom Diederik leer om te huil". (In Vergesigle). Pretoria: Van Schaik.

\section{Sekondêre bronne}

BOTHA, E. 1960. Oordele in oënskou 1. J. van Melle: Bart Nel - die vraag na Fransina se goeie trou. Standpunte. 13(6): 18-23, Aug.

BRINK, André P. 1976. "Algaande na die ver ruim lig": Aantekeninge by Bart Nel. Tydskrif vir Lellerkunde. Nuwe reeks XIV: 3,35-45, Aug.

JANSE VAN RENSBURG, L. (samest.) 1976. Johannes van Melle (18871953). Bibliografie. Universiteit van Stellenbosch. Departement Biblioteekkunde. (Mikrofiche).

JONCKHEERE, W.F. 1968. Johannes van Melle. Realist tussen twee werelden. Pretoria: Van Schaik.

TRUTER, H.W. 1965. Oom Daan en oom Diederik. Standpunte. 18 (3):44-49.

VAN DER WALT, P.D. 1966. Die wye eensaamheid in Bart Nel. Standpunte. 20 (2): 16-18.

VENTER, L.S. 1982. Die topologiese verhaalruimte in Van Melle se Bart Nel. (In Ruimte as epiese kategorie. 'n Ondersoek aan die hand van Afrikaanse en Nederlandse romans). Proefskrif (D.Phil.) PU vir CHO. 